\title{
The examination of stress in the first clinical experience Nahid Asemanrafat*
}

\author{
Address: Medicalscience Un, Iran
}

* Corresponding author

\author{
from International Society on Brain and Behaviour: 2nd International Congress on Brain and Behaviour \\ Thessaloniki, Greece. 17-20 November 2005 \\ Published: 28 February 2006 \\ Annals of General Psychiatry 2006, 5(SuppI I):SI09 doi:I0.I I86/I744-859X-5-SI-SI09
}

\section{Background}

In the modern world, the rate of changes and acquiring of experiences had been accelerated and we can neither be safe from he distressing factors resulting from such changes or experiences nor can we eliminate them. There fore, it is necessary to specify these factors.

In a research carried out in 1998, the distressing factors were identified as fear from making mistakes and not being accepted by the educator and fear from deficiencies.

\section{Materials and methods}

This is a descriptive study in witch 59 nursing students who experienced the first session by questionnaires.

\section{Results}

In this study $62 / 7 \%$ of the subjects said that they were not familiar with clinical setting and $45.8 \%$ said that they feared from the educators evaluation.

\section{Discussion}

The findings indicate that the distressing factors must be identified during the first clinical experiences and we must use different strategies to reduce or eliminate these factors and in this way increase the students movation and interest to their job. 